\title{
NO/cGMP signalling in platelets
} Elisabeth Schinner* and Jens Schlossmann

\author{
Address: Department of Pharmacology, University Regensburg, Germany \\ Email: Elisabeth Schinner* - elisabeth.schinner@chemie.uni-regensburg.de \\ * Corresponding author
}

\author{
from 4th International Conference of cGMP Generators, Effectors and Therapeutic Implications \\ Regensburg, Germany. 19-21 June 2009 \\ Published: II August 2009 \\ BMC Pharmacology 2009, 9(Suppl I):P62 doi:I0.1 186/I47I-2210-9-SI-P62
}

This abstract is available from: http://www.biomedcentral.com/I47I-22/0/9/SI/P62

(c) 2009 Schinner and Schlossmann; licensee BioMed Central Ltd.

\section{Background}

$\mathrm{NO} /$ CGMP-signalling is important for the inhibition of platelet aggregation. The cGMP dependent protein kinase I plays thereby the key role in the signal cascade of $\mathrm{NO} /$ cGMP. It is already known that the interaction of the cGKI substrate IRAG with the $\mathrm{IP}_{3} \mathrm{RI}$ is essential for the $\mathrm{NO} /$ cGMP dependent inhibition of platelet aggregation. To specify the relevance of IRAG signalling for platelet function, IRAG deficient murine mutants were analysed. Diverse agonists like thrombin, thromboxane A2 and collagen induced platelet aggregation and granule secretion.

\section{Results}

In wild-type platelets the activation was inhibited by NOdonors and a cGMP-analogue whereas in IRAG-deficient platelets the inhibiting effect of NO/cGMP was almost abolished. Furthermore NO/cGMP dependent inhibition of agonist-induced activation of the fibrinogen receptor GPIIb/IIIa and the resulting fibrinogen binding was strongly reduced in IRAG deficient platelets compared to wild-type platelets.

\section{Conclusion}

These findings delineate the predominant physiological role of IRAG for the NO/cGMP dependent inhibition of platelet aggregation and granule secretion. 